\title{
CAPítTLLO 6
}

\section{METODOLOGIA REFLEXIVA \\ UM OLHAR PARA A DOCUMENTAÇÃO \\ DE PROFESSORES PARA INTRODUÇÃO AO \\ ENSINO DE FUNÇÃO NO 10 ANO DO \\ ENSINO MÉDIO}

Armênio Lannes Xavier Neto

Maria José Ferreira da Silva

\section{INTRODUÇÃO}

O presente capítulo tem por objetivo abordar a relevância da metodologia de investigação reflexiva na análise da documentação de professores quando introduzem o ensino de função no $1^{\circ}$ ano do Ensino Médio - EM. É parte de um estudo que se encontra em andamento, com um coletivo de professores em uma formação continuada, sob a perspectiva dos quadros teóricos da Orquestração Instrumental - OI e da Abordagem Documental do Didático - ADD.

A formação continuada foi planejada de maneira a possibilitar o estudo do fenômeno da gênese documental, considerando os princípios propostos pela metodologia de investigação reflexiva e tendo como pano de fundo a apropriação de um modelo para introduzir o ensino de função no $1^{\circ}$ ano do EM a partir de função de uma variável real com várias sentenças matemáticas - FVSM.

Ela foi estruturada para ser desenvolvida em duas etapas: uma denominada "preparação", relativa à sua organização prévia, com o objetivo de mapear recur$\operatorname{sos}^{24}$ e conhecimentos dos participantes a respeito do ensino de função, e uma

24 O termo recurso é pensado, de acordo Gueudet e Trouche (2018, p. 7, tradução nossa) "como uma variedade de artefatos tais como um livro texto, um software, uma lista de exercícios, 
segunda, estritamente vinculada à primeira, denominada "execução", destinada ao processo de elaboração, aplicação e crítica de uma Sequência Didática - SD para tal ensino.

A temática função foi escolhida para ser objeto de estudo na formação continuada pois, de acordo com Oliveira (1997, p. 15), "trata-se de um tema que acaba por aglutinar praticamente todo o conhecimento matemático" que possui diretrizes bem definidas quanto a seu ensino nos documentos curriculares nacionais como os Parâmetros Curriculares Nacionais do Ensino Médio - PCN+ e da Base Nacional Comum Curricular - BNCC. O PCN+ salienta que o ensino de função "permite ao aluno adquirir a linguagem algébrica como a linguagem das ciências, necessária para expressar a relação entre grandezas e modelar situações-problema” (BRASIL, 2000, p. 121), para construir modelos descritivos dentro e fora da matemática.

O documento sugere também, que o ensino do tema deve priorizar abordagens excessivamente formais, enquanto que a BNCC propõe que a noção intuitiva de função "possa ser explorada por meio da resolução de problemas envolvendo, a variação proporcional direta entre duas grandezas (sem utilizar regra de três)" (BRASIL, 2018, p. 227) e ainda, que os estudantes estabeleçam conexões entre variável e função e entre incógnita e equação.

Realizada esta breve introdução apresenta-se na sequência, a metodologia de investigação reflexiva, uma breve descrição da estrutura da formação continuada e as etapas de preparação e execução.

\section{A METODOLOGIA DE INVESTIGAÇÃO REFLEXIVA}

A investigação reflexiva foi apresentada como uma metodologia de pesquisa empírica no momento da proposição da ADD por Trouche, Gueudet e Pepin (2008) tendo como caraterísticas principais, a reflexão do professor sobre seu trabalho de documentação e seu envolvimento na etapa de coleta de dados. Posteriormente, foi formatada a partir da constatação de que o estudo do trabalho de documentação dos professores deveria considerar os seguintes elementos:

\footnotetext{
a diversidade dos recursos que alimentam esse trabalho e dele resultam, a variedade das interações (coletivas, institucionais e sociais e o tempo necessário para o desenvolvimento das gêneses documentais. (TROUCHE; GUEUDET; PEPIN, 2018, p. 8, tradução nossa).
}

uma reunião pedagógica ou ainda uma discussão com um colega”. 
Essa reflexão a respeito da documentação de professores, que é de natureza epistemológica, levaram os autores a desenvolver a metodologia de investigação reflexiva do trabalho documental dos professores que se fundamenta nos seguintes princípios:

$1^{\circ}$ ) acompanhamento a longo prazo;

$\left.2^{\circ}\right)$ acompanhamento dentro e fora da sala de aula;

$3^{\circ}$ ) acompanhamento reflexivo do trabalho de documentação;

$4^{\circ}$ ) ampla coleta dos recursos materiais utilizados e produzidos no trabalho de documentação;

$\left.5^{\circ}\right)$ confrontação permanente das opiniões do professor a respeito de seu trabalho de documentação. (TROUCHE; GUEUDET; PEPIN, 2018, p. 7, tradução nossa).

O princípio de acompanhamento a longo prazo está diretamente relacionado ao desenvolvimento do fenômeno da gênese documental. Como mencionado por Trouche, Gueudet e Pepin (2018), as gêneses são processos contínuos que exigem tempo para evoluir, bem como para observá-las. Parte integrante desse processo - os esquemas -, de acordo com Trouche, Gueudet e Pepin (2018, p. 9, tradução nossa), "também se desenvolvem em longos períodos de tempo" e tal qual a gênese, demandam um período extenso de observação.

O segundo princípio da metodologia de investigação reflexiva, voltado ao acompanhamento dentro e fora da sala de aula tem por intuito compreender a extensão do trabalho documental do professor. Ainda que a sala de aula constitua-se no local em que os professores implementam, revisam, adaptam e melhoram suas aulas e recursos, esse trabalho também pode ocorrer "fora dela, como em casa, em uma reunião pedagógica, ou ainda em uma formação continuada" (p. 23, tradução nossa) fazendo com que seja necessário considerá-los tão importantes quanto os eventos que ocorrem dentro da sala de aula.

De acordo com Wang (2019, p. 81, tradução nossa) "o princípio de ampla coleta dos recursos materiais usados e produzidos no trabalho de documentação está conectado a própria ideia de recurso". O amplo significado do termo recurso implica em que se considere aqueles de origem digital ou não, mas também todo o tipo de recurso utilizado pelo professor para o ensino e a aprendizagem de matemática dentro e fora da sala de aula. 
O princípio de acompanhamento reflexivo do trabalho de documentação possui a peculiaridade de envolver o professor diretamente com a coleta de dados. Segundo Messaoui (2019, p. 94, tradução nossa) "a participação do professor é uma necessidade prática pois só ele tem acesso a todo o seu trabalho documental".

O último princípio, proposto pela metodologia reflexiva, relacionado a confrontação permanente das opiniões do professor e seu trabalho de documentação possibilita ao pesquisador, de acordo com Trouche, Gueudet e Pepin (2018, p. 6, tradução nossa), "revisar dados coletados e sugerir que o professor interprete traços de seu trabalho documental".

Com base nesses princípios, segundo os autores, "algumas estratégias de coleta de dados foram desenvolvidas de maneira a adaptar os princípios a diferentes contextos e questões de pesquisa" (p. 7, tradução nossa). Uma dessas ferramentas, a Representação Esquemática do Sistema de Recursos - RESR, pode permitir que o pesquisador identifique traços da evolução do trabalho documental do professor convidando-o a representar em uma folha de papel a estrutura de recursos utilizada em sua atividade docente. Pode-se observar na Figura 1, um exemplo de uma RESR em que é possível identificar o recurso sala de aula ocupando o centro do sistema de recursos de um professor e, ligados a ela, os recursos: giz e lousa, apostila do aluno, sala de informática, livro didático, reunião, jogos e data show.

Figura 1 - Exemplo de RESR

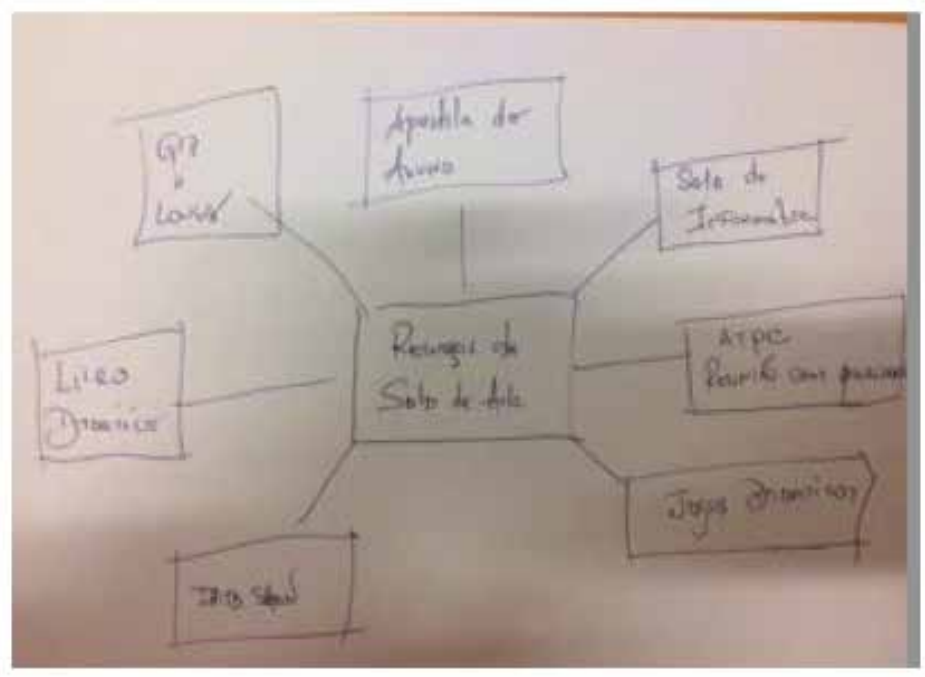

Retirado de: Xavier Neto, Silva e Trouche (2019, p. 308). 
A representação desse esquema também possibilita ao pesquisador inferir, segundo Gueudet e Trouche (s/d, p. 2), "sobre a organização da atividade profissional do professor", além de proporcionar uma oportunidade para que reflita sobre seu trabalho de documentação. Segundo Trouche, Gueudet e Pepin (2018, p. 8, tradução nossa) "desde a proposição da ADD, a ferramenta RESR tem sido aprimorada em várias direções", como nas contribuições de Hammoud (2012) que propôs utilizá-la na descrição de mapas mentais ou na investigação de Rocha (2018) que renomeou a RESR para Mapeamento Reflexivo do Sistema de Recursos do Professor - RMRS, com o intuito de reforçar a importância da reflexão no processo de documentação do professor.

O envolvimento do professor com a coleta de dados, a respeito de seu trabalho documental, conduziu à proposição do contrato metodológico, elaborado por Sabra (2012), que procura articular, de acordo com Trouche, Gueudet e Pepin (2018, p. 8, tradução nossa) "a relação do professor com o pesquisador a fim de que o processo de coleta de dados ocorra com fluidez".

A utilização da visita aos professores também tem sido utilizada como estratégia para acompanhar o trabalho de documentação, fora do ambiente da sala de aula, bem como contemplar o princípio da ampla coleta de recursos materiais utilizados e/ou produzidos pelo professor e são acompanhadas de entrevistas. A respeito do local em que as entrevistas deveriam ocorrer, cabe esclarecer que algumas investigações como Hammoud (2012) e Sabra (2012), apontaram a residência como mais adequada por ser o local onde os professores, geralmente, planejam seu trabalho documental. Entretanto, trata-se apenas de uma sugestão, pois não há na metodologia reflexiva uma indicação precisa do lugar em que as visitas devam ocorrer. Além disso, segundo Trouche, Guedet e Pepin (2018, p. 9, tradução nossa), "a metodologia de investigação reflexiva fornece diretrizes para as escolhas metodológicas, cabendo aos pesquisadores fazer escolhas ao longo do percurso investigativo".

Após a apresentação da metodologia de investigação reflexiva apresenta-se uma breve descrição da estrutura da formação continuada em que foi utilizada.

\section{BREVE DESCRIÇÃO DA ESTRUTURA DA FORMAÇÃO CONTINUADA}

A formação continuada, aqui apresentada, foi estruturada a partir dos cinco princípios da metodologia de investigação reflexiva com o intuito de acompanhar o processo de documentação de um grupo de professores a respeito do ensino de função na educação básica. Como o ponto central dessa metodologia 
são os acompanhamentos dos professores, tivemos que elaborar uma estrutura de formação que nos permitisse observar as gêneses documentais que, de acordo com Trouche, Gueudet e Pepin (2018, p. 12, tradução nossa), "são processos que necessitam de longos períodos de observação" sem indicações do tempo demandado para seu estudo.

Para isso se estruturou a formação continuada em duas fases: a fase de preparação, planejada pelos autores de modo a iniciar o processo de acompanhamento reflexivo a longo prazo do trabalho documental dos participantes, dentro e fora da sala de aula, e contemplar o princípio da ampla coleta de materiais utilizados e produzidos no trabalho de documentação; e a fase de execução, pensada de maneira a ampliar esse processo por meio da observação do confronto das opiniões dos professores a respeito de seu trabalho de documentação.

Os dados obtidos na fase de preparação foram coletados por intermédio do preenchimento de questionários informativos e diário de bordo, diálogos produzidos em fóruns de discussão no ambiente virtual moodle, áudios de entrevistas individuais e recursos utilizados e/ou produzidos pelos participantes. Na fase de execução, os dados foram obtidos por meio de protocolos de observação preenchidos por um participante observador, diário de bordo, áudio, vídeo e diálogos produzidos durante os encontros presenciais, recolha dos recursos físicos e/ou digitais utilizados e/ou produzidos por participantes e seus alunos. Para organizar o material produzido em áudio foi realizada sua transcrição integral com auxílio do programa Express Scribe,25 versão 8.20 em português.

Após a breve apresentação da formação continuada apresenta-se, a seguir, detalhes de cada uma de suas fases.

\section{A FORMAC̦ÃO CONTINUADA EA FASE dE PREPARAÇÃ̃o}

Para dar início ao acompanhamento do trabalho de documentação da formação continuada, a fase de preparação foi organizada entre os meses de Julho e Agosto de 2019 (Figura 2), tendo por objetivos proceder com a seleção dos participantes, preparar questionários, o funcionamento do diário de bordo e fóruns de discussão, como ocorreriam as visitas e como aconteceriam os encontros.

O primeiro passo dessa fase foi selecionar os participantes. Para isso, utilizou-se como critério que os professores ministrassem aulas de matemática para

\footnotetext{
25 “Express Scribe é um software reprodutor de áudio profissional para PC ou Mac projetado para ajudar a transcrever gravações de áudio". Retirado de: https://www.nch.com.au/scribe/ index.html.
} 
o $1^{\mathrm{o}}$ ano do $\mathrm{EM},{ }^{26}$ devido à temática função ser desenvolvida ao longo desse ano letivo em escolas públicas e/ou privadas, conforme sugerem os documentos curriculares nacionais. $\mathrm{O}$ segundo passo foi decidir como os encontros de formação ocorreriam e escolheu-se por encontros de participação a distância e presenciais a fim de possibilitar o acompanhamento do trabalho documental dos participantes durante todo o período em que a formação continuada acontecesse. Para o primeiro foram planejados três modalidades de participação: o preenchimento de questionários, do diário de bordo e a viabilização de fóruns de discussão que ocorreriam pela ferramenta Moodle.27

Figura 2 - Estrutura de funcionamento da Fase de Preparação

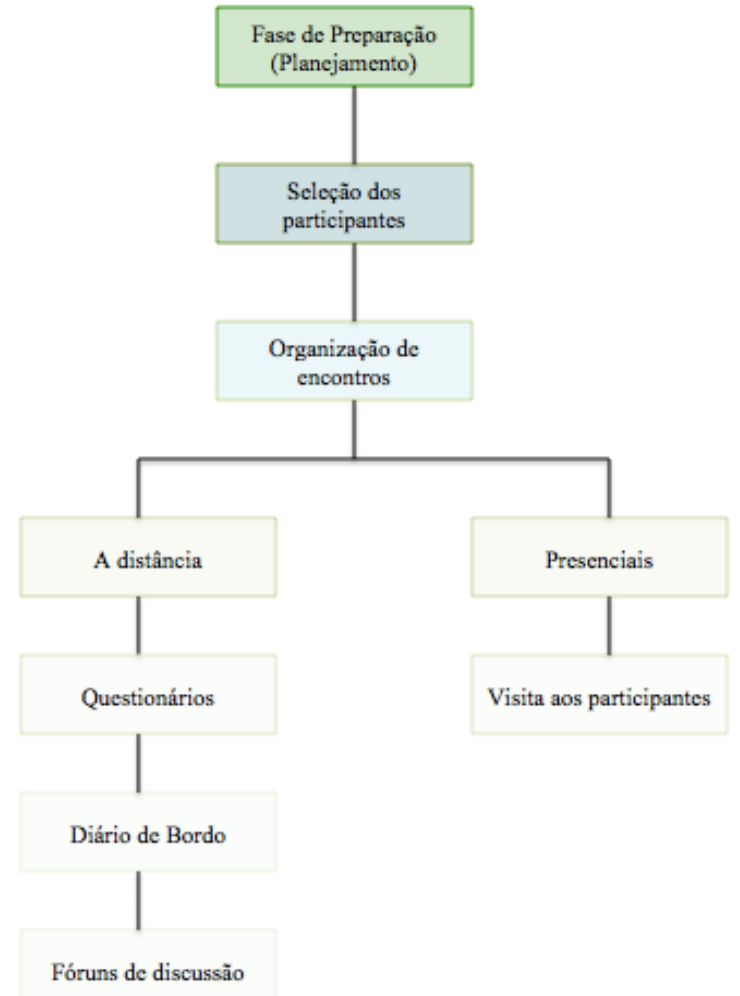

Fonte: Produção dos autores.

26 Normalmente a temática função é desenvolvida nesse ano letivo em escolas públicas e/ou privadas, conforme orientação dos documentos curriculares nacionais.

27 Segundo Assis (2010, p. 29) Moodle é um software livre destinado a auxiliar educadores a criarem cursos via Internet ou apoiar cursos presenciais. Este sistema de educação é também chamado de Sistema de Gerenciamento de Aprendizagem. Mais informações sobre o Moodle podem ser obtidas no Site http://moodle.org. 
O uso de questionários informativos teve por objetivo elaborar um perfil pessoal e profissional de cada participante e reunir informações que detalhassem sua relação com recursos e seus conhecimentos. Os dados obtidos por esse instrumento foram organizados em planilhas eletrônicas na forma de tabelas e/ ou gráficos que permitiram organizar as informações a respeito do perfil profissional e pessoal de cada um dos participantes. A escolha dos temas apresentados nos questionários e o conteúdo das perguntas foram adaptados de contribuições propostas por Gueudet e Trouche (s/d, p. 2) e versaram sobre temas relativos à formação, ambiente de trabalho, relação com as TIC $^{28}$ e a relação dos participantes com a matemática enquanto área de conhecimento e seu ensino. A construção de tal perfil também auxiliou no processo de preparação das entrevistas individuais e, ainda, complementar informações obtidas pelo questionário.

Entendeu-se também que o preenchimento de um diário de bordo, no ambiente virtual, seria capaz de oferecer detalhes das atividades dos participantes em um longo período que permitiria compreender, com mais precisão, os recursos utilizados e a natureza das atividades desenvolvidas pelos professores, tanto dentro, quanto fora da sala de aula.

A utilização da ferramenta fórum de discussão foi planejada para acompanhar discussões e troca de informações entre os participantes e, assim, o desenvolvimento da documentação dos professores, bem como viabilizar a coleta de recursos utilizados e/ou produzidos, uma vez que é possível carregar ou descarregar arquivos durante as postagens.

Enfim, prevíamos que os ambientes virtuais proporcionassem um acompanhamento estreito do trabalho de documentação do grupo, na medida em que oferece a possibilidade da coleta de recursos utilizados e produzidos, além de constituírem-se em um canal de comunicação constante entre o pesquisador e os participantes.

Considerou-se como sujeitos de pesquisa os oito professores que participaram da formação continuada, provenientes da rede pública e/ou privada, dos quais, apresenta-se, no Quadro 1, uma síntese do perfil pessoal e profissional identificados por nomes fictícios.

Ainda, na fase de preparação, foram planejadas e realizadas visitas e entrevistas individuais com os participantes, nos estabelecimentos de ensino em que trabalhavam, com o intuito de acompanhar o trabalho documental fora do ambiente da sala de aula, bem como acessar o conjunto de recursos utilizados e/ ou produzidos para o ensino de função. No momento da entrevista foi proposto

28 Tecnologias da informação e comunicação. 
aos participantes a elaboração da RESR como estratégia de reflexão sobre o trabalho documental.

Durante a preparação foi combinado com os professores que a fase de execução ocorreria por meio de encontros presenciais semanais, com duração de 3 horas, tendo com início no mês de agosto de 2019 no campus Consolação da PUC-SP, com o suporte do ambiente virtual Moodle. Para o primeiro encontro um e-mail foi enviado aos participantes informando detalhes de sua realização.

Quadro 1. Perfil pessoal e profissional dos participantes da formação continuada

Alfredo, Licenciado em Matemática, com 7 anos de experiência profissional, 4 anos de experiência no ensino médio, trabalha em escola privada, possui carga horária de $22 \mathrm{~h} /$ semanais, as salas de aula de sua escola são equipadas com datashow e um computador para o professor, há notebooks disponíveis aos estudantes (quando solicitado pelo professor), as TIC possuem papel secundário em suas aulas e considera a geometria um tópico difícil de ser ensinado.

Antônio, Licenciado em Matemática, com 9 anos de experiência profissional, 5 anos de experiência no ensino médio, trabalha na Prefeitura de São Paulo e em uma escola privada, possui carga horária de $30 \mathrm{~h} / \mathrm{semanais,} \mathrm{em} \mathrm{ambas} \mathrm{existem} \mathrm{salas} \mathrm{equipadas} \mathrm{com}$ computadores, acesso à internet, calculadoras e tablets disponíveis aos alunos, as TIC possuem papel secundário em suas aulas, e considera não existir dificuldade em ensinar qualquer tópico da matemática.

Bruno, Licenciado em Matemática, com 12 anos de experiência profissional, 8 anos de experiência no ensino médio, trabalha no Instituto Federal da cidade de Itaquaquecetuba - SP, possui carga horária de 40h/semanais, a instituição possui laboratório de informática onde é possível desenvolver atividades e os alunos possuem celulares pessoais, as TIC possuem papel secundário em suas aulas, e considera álgebra e estatística como tópicos difíceis para serem ensinados.

Fabíola, Licenciada em Matemática, com 10 anos de experiência profissional, 7 anos de experiência no ensino médio, trabalha no Instituto Federal da cidade de Itaquaquecetuba - SP, possui carga horária de $30 \mathrm{~h} / \mathrm{semanais,} \mathrm{a} \mathrm{instituição} \mathrm{possui} \mathrm{laboratório} \mathrm{de} \mathrm{informática}$ onde é possível desenvolver atividades e os alunos possuem celulares pessoais, as TIC possuem papel secundário em suas aulas e considera a álgebra como difícil de ser ensinada.

Gabriel, Formado em Engenharia Mecânica, com 2 anos de experiência profissional, 2 anos de experiência no ensino médio, trabalha em duas escolas privadas, possui carga horária de 30h/semanais, as instituições são equipadas com datashow e um computador para o professor, notebooks disponíveis aos estudantes (quando solicitado pelo professor) além de Laboratório de informática, as TIC possuem papel secundário em suas aulas e considera a álgebra como difícil de ser ensinada. 
Lucas, Licenciado em Matemática, com 1,5 anos de experiência profissional, 1,5 anos de experiência no ensino médio, trabalha em escola privada, possui carga horária de $25 \mathrm{~h} /$ semanais, as salas de aula de sua escola são equipadas com datashow e um computador para o professor, notebooks disponíveis aos estudantes (quando solicitado pelo professor), as TIC possuem papel secundário em suas aulas e considera não existir dificuldade em ensinar qualquer tópico da matemática.

Luiz, Licenciado em Matemática, com 20 anos de experiência profissional, 7 anos de experiência no ensino médio, trabalha em uma escola estadual e na prefeitura da cidade de Embu Guaçu - SP, possui carga horária de 40h/semanais, há laboratório de informática nas duas escolas onde trabalha, as TIC possuem papel secundário em suas aulas e considera a aritmética como difícil de ser ensinada.

Luiza, Licenciada em Matemática, com 20 anos de experiência profissional, 16 anos de experiência no ensino médio, trabalha em uma Escola Estadual na cidade de São Paulo, possui carga horária de $27 \mathrm{~h} /$ semanais, na sua escola há laboratório de informática (com pouca utilização), os alunos possuem celulares pessoais, as TIC possuem papel secundário em suas aulas e considera não existir dificuldade em ensinar qualquer tópico da matemática.

Fonte: Produção dos autores.

Alguns de nossos resultados iniciais apontaram obstáculos na implementação do diário de bordo e em efetivar visitas às residências dos participantes. Inferiu-se inicialmente tratar-se de fenômenos ligados à cultura do professor brasileiro, que não tem por hábito confeccionar documentos tão minuciosos sobre sua prática profissional, como no caso do diário de bordo, e em aceitar debater detalhes de sua atividade profissional no âmbito de sua residência.

Após a apresentação da fase de preparação da formação continuada será detalhado, a seguir, a fase de execução.

\section{A FORMAÇÃ̃O CONTINUADA E A FASE DE EXECUÇ̃̃̃O}

Para procurar responder desafios específicos provocados por nossa problemática, desenvolvemos na fase de execução da formação continuada que aconteceu durante os meses de agosto a dezembro de 2019, um dispositivo de acompanhamento do trabalho documental dos participantes. Ele consistiu na vivência de um conjunto de situações articuladas por OIs visando a elaboração coletiva, aplicação e crítica de uma SD para introduzir o ensino de função a partir de FVSM. O acompanhamento dos esquemas documentais e classes de situações a que se referiam durante os diferentes momentos de construção da SD possibilitou acompanhar a evolução da documentação dos participantes. 
Cabe esclarecer que a noção de situação se refere a situações profissionais que o professor enfrentará durante sua atividade profissional alinhada às proposições de Vergnaud (1998), em que a relação entre sujeito e artefato é proporcionada por uma situação que exigirá do indivíduo, a mobilização de esquemas já existentes ou em desenvolvimento.

$\mathrm{Na}$ fase de execução planejamos orquestrar um conjunto de situações de ensino relacionadas à introdução do ensino de função para que os participantes da formação mobilizassem classes de situação para enfrentá-las. Quando a situação fosse familiar ao participante, supôs-se que extrairia de seu repertório referências necessárias para lidar ela com um certo grau de automatismo. Por outro lado, quando a situação fosse nova, ele procuraria inicialmente compará-la a uma classe de situações conhecidas e, por tentativa e erro, poderia recompor seus esquemas existentes e tentar adaptar-se à situação para criar, gradativamente, uma nova classe. Segundo Trouche, Gueudet e Pepin (2018, p. 5, tradução nossa), "o conceito de esquema (Vergnaud, 1998) é central na ADD, pois está fortemente ligado ao conceito de classes de situações, que designa, em nosso contexto, um conjunto de situações profissionais", correspondentes a um mesmo objetivo da atividade.

Para viabilizar o princípio de acompanhamento a longo prazo, proposto pela metodologia de investigação reflexiva, a fase de execução foi desenvolvida para ocorrer em três etapas: elaboração coletiva, aplicação e crítica da SD.

Para a implementação da primeira etapa, de elaboração coletiva da SD, foram idealizadas situações que requereram a organização de três OIs desenvolvidas ao longo de encontros presenciais, com suporte do ambiente virtual Moodle, cujos objetivos e datas de realização são mostrados no Quadro 2.

Quadro 2. Objetivo e data dos encontros presenciais durante a elaboração coletiva da SD

\begin{tabular}{|c|c|}
\hline Situação & Período \\
\hline Reflexão & $24 / 08 / 2019$ \\
\hline Formação & $31 / 08,21 / 09,28 / 09$ e $05 / 10 / 2019$ \\
\hline Organização & $19 / 10$ e $26 / 10 / 2019$ \\
\hline
\end{tabular}

Fonte: Produção do autores.

A primeira situação, de reflexão, foi planejada para ocorrer em um encontro presencial com suporte do ambiente Moodle com o objetivo de proporcionar reflexões a respeito das escolhas feitas pelos participantes para introduzir o ensino de função no $1^{\circ}$ ano do EM. Para isso, foi proposto ao grupo a elaboração de uma SD para tal a partir de situações de ensino cujos recursos foram escolhi- 
dos por eles(as) e que demandaram a mobilização de classes de situações. Foi estabelecida como hipótese que os participantes construiriam a SD priorizando a introdução ao ensino de função, a partir de funções do tipo afim, como uma única expressão e comportamento regular. Tal hipótese foi alicerçada a partir de estudos obtidos em investigações conduzidas por Eves (1990), Elia, Panaoura, Eracleus e Gagatsis (2006), Huh (2009), dentre outros, que indicaram ainda como consequência dessa escolha, a produção de obstáculo didático durante o processo de aprendizagem de função.

A fim de que a situação de reflexão planejada favorecesse a mobilização e/ ou o desenvolvimento de esquemas documentais pelos participantes, ao longo do processo de elaboração coletiva da SD, foram elaborados uma configuração didática $^{29}$ e um modo de execução ${ }^{30}$ que se constituiu na a OI-1. Nesse sentido planejou-se a organização de um fórum de discussão no ambiente Moodle para dar suporte às discussões presenciais e o arranjo físico, além da gestão do tempo e tecnologias para a realização do encontro presencial. No fórum de debates, os participantes encontrariam um espaço específico para descarregar a(s) situações de ensino que julgassem convenientes para introduzir o ensino de função no $1^{\circ}$ ano do EM, além de digitar por meio de postagem suas justificativas para tal escolha.

Em razão do número reduzido de participantes, programou-se que durante o encontro presencial haveria um único grupo de trabalho que disporia de $90 \mathrm{mi}$ nutos para a construção da SD e outros 60 minutos para participar de um debate reflexivo coordenado pelo formador a respeito de suas escolhas para introduzir o ensino de função.

A organização do espaço físico para a realização desse encontro presencial em uma sala de aula da PUC-SP, apontada na Figura 3, mostra as posições ocupadas pelos participantes, pelo pesquisador (exercendo a função de formador), do observador e do profissional de vídeo.

\footnotetext{
29 De acordo com Trouche (2004, p. 8, tradução nossa), “a configuração didática é um arranjo dos artefatos dentro do ambiente em que ocorre a situação de aprendizagem".

30 De acordo com Trouche (2004, p. 9, tradução nossa), "um modo de exploração refere-se à maneira com o qual um professor decide colocar em prática o arranjo dos artefatos a fim de fazer valer suas intenções didáticas".
} 
Figura 3 - Panorama da OI-1

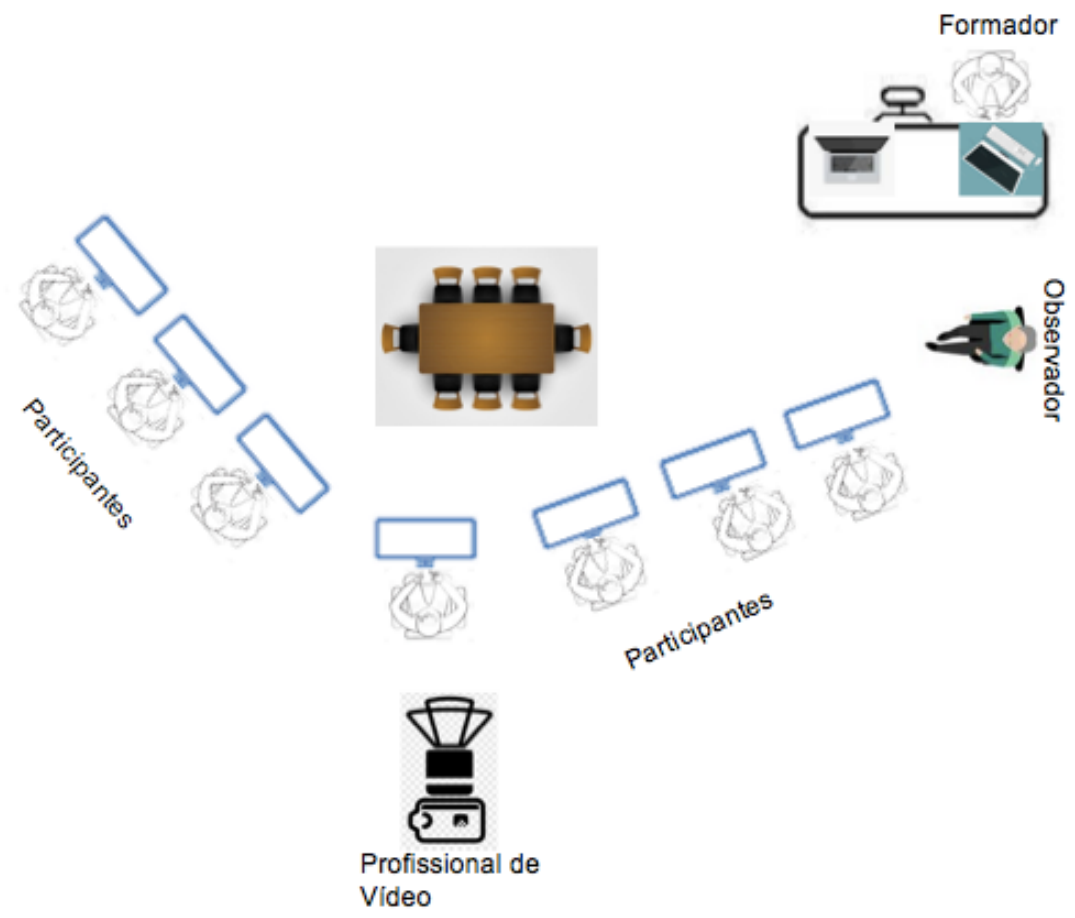

Fonte: Produção dos autores.

Planejou-se que a performance didática ${ }^{31}$ da OI-1 oportunizasse um balanço a respeito do que foi planejado e eventualmente alterado durante a primeira situação, ocasião em que seria possível verificar a viabilidade das intenções que foram planejadas e o êxito da OI-1. Nessa perspectiva esperou-se que a proposta potencializasse a produção de reflexões sobre as escolhas dos participantes para introduzir o ensino de função e abrisse caminho para abordá-la, posteriormente, por meio de FVSM. Ao longo da situação de reflexão planejou-se acompanhar o trabalho de documentação dos participantes, bem como coletar todos os recursos que porventura fossem produzidos e/ou mobilizados. Resultados preliminares obtidos durante a vivência da performance didática da OI-1 apontaram que a hipótese proposta inicialmente foi verificada integralmente.

Segundo Drijvers et al. (2010, p. 216) "a performance didática está relacionado ao desempenho alcançado pelo cenário projetado, em que se faz possível, verificar a viabilidade das intenções e o sucesso da realização da OI". 
A segunda situação, de natureza formativa, foi planejada para ocorrer em quatro encontros presenciais com suporte do ambiente Moodle, a partir de quatro situações de ensino para introduzir função no $1^{\circ}$ ano do EM a partir da FVSM, cujos recursos foram intencionalmente selecionados pelo formador.

Considerando o princípio de acompanhamento de longa duração, proposto pela metodologia de investigação reflexiva e, o fato de que, segundo Trouche, Gueudet e Pepin (2018, p. 8, tradução nossa) "as gêneses são processos em desenvolvimento e os esquemas se desenvolvem em longos períodos”, essas quatro situações de ensino foram idealizadas de modo a serem vivenciadas em um período de tempo razoável ao longo da formação continuada.

Conjecturou-se que o processo de resolução coletiva exigiria dos participantes a mobilização de classes de situações e possibilitasse a identificação de esquemas documentais desenvolvidos e/ou mobilizados que permitiriam o acompanhamento do processo de documentação dos participantes. O primeiro encontro, ocorrido em 31/08/2019, foi planejado para resgatar as discussões coletivas da OI-1 e para debater a primeira situação de ensino e os outros três, ocorridos em 21/09, 28/09 e 05/10/2019, para resolver e debater as demais situações de ensino.

Para implementar a situação de formação planejada foram elaborados uma configuração didática e um modo de execução que constituíram a OI-2. Durante esse processo foram feitas análises a priori de cada uma das quatro situações de ensino propostas aos participantes, que segundo Lucena (2018, p. 244), "são fundamentais para prever eventos inerentes a essas, e, os que possam comprometer o bom desempenho dos participantes". Essas previsões incluem o planejamento de ações alternativas para, eventualmente, contornar eventos que possam comprometer o andamento da orquestra de cada uma das situações lideradas pelo formador.

Na Figura 4 apresenta-se uma das situações de ensino proposta aos participantes. 
Figura 4 - Situação de ensino proposta aos participantes durante a OI-2

PROBLEMA.

1. Um ponto $M$ se desloca sobre o lado de um quadrado $A B C D A$ cujo cada lado meça 4 y.m. (figura abaixo). Designamos como $x$ a medida referente ao comprimento do trajeto de $\mathrm{A}$ até $\mathrm{M}$.

a) Expresse a área $a(x)$ da parte colorida, segundo a posição do ponto $M$;

b) Represente graficamente a aplicação correspondente
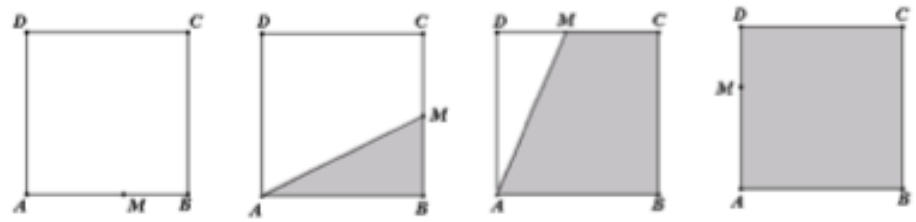

2. Retome as mesmas tarefas dadas na primeira questão, e considere $\mathrm{ABCD}$ como sendo um retângulo de comprimento 4 e largura 2 conforme a figura abaixo.
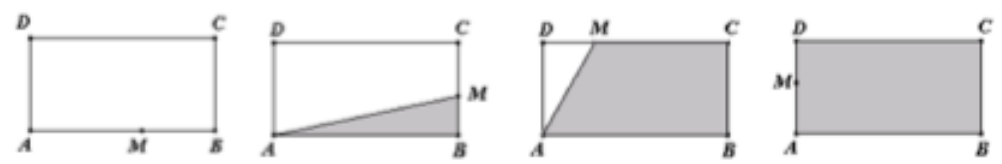

3. Retome as mesmas tarefas dadas na primeira questão e considere ABCD como sendo um losango cujos lados medem 4 yum e o ângulo $C$ $=60^{\circ}$

Fonte: Callection Mathématiques. IPN, 1991, Rep. De Mali, $9^{\circ}$ anofee e $10^{\circ}$ sicences, HatiecLibraicie Nouvelle

Fonte: Retirado de Xavier Neto (2016).

A situação de ensino (Figura 4) foi concebida originalmente em um contexto intramatemático, ${ }^{32}$ inserida em um quadro geométrico bem conhecido dos estudantes, composta por funções do tipo afim e provocando ainda, segundo Almouloud (2016, p. 9) "o surgimento de questões do tipo: o que os alunos vão fazer?; o trabalho será desenvolvido em grupo?; que instruções fornecer?; que conhecimentos poderão ser socializados?", suscitando reflexões a respeito do papel desempenhado por estudantes e professores no processo de construção do conhecimento de função.

Durante os encontros para realização dos quatro encontros presenciais, da situação de formação, ocorreu uma nova organização do espaço físico, pois ocorreram em um dos laboratórios de informática da PUC-SP. Na Figura 5, pode-se observar as posições ocupadas pelos participantes, pelo pesquisador que exercia a função de formador, do observador e do profissional de vídeo.

32 Segundo Laudares (p. 6, 2013) "tratam-se de abordagens de situações no interior da Matemática". 
Figura 5 - Panorama da OI-2

Tela Branca e Datashow
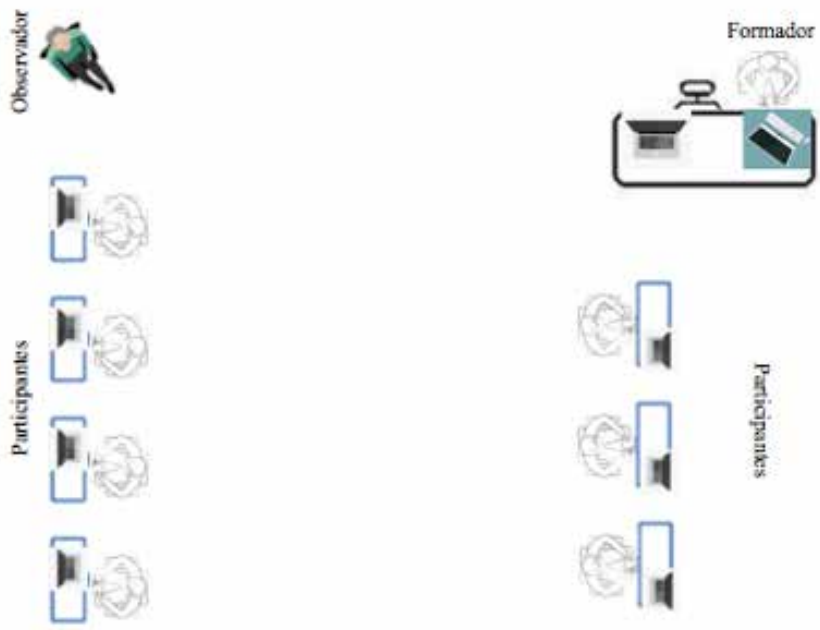

Profissional de

Video

Fonte: Produção dos autores.

Planejou-se que a performance didática da OI-2 trouxesse elementos acerca do que foi planejado e efetivamente alcançado ao longo da situação de formação, ocasião em que seria possível verificar a viabilidade das intenções que foram planejadas e o êxito da OI-2 à luz das análises a priori das situações. Nessa perspectiva considerou-se que a resolução coletiva das situações de ensino, propostas pelo formador, criariam condições para a produção de desequilíbrios nas escolhas dos professores para introduzir o ensino de função no $1^{\circ}$ ano do EM.

A terceira situação, de organização, foi pensada para ocorrer em dois encontros presenciais e, de maneira similar às duas situações anteriores, com suporte do ambiente Moodle.

Considerando os princípios do acompanhamento a longo prazo, reflexão e confrontação permanente do seu trabalho documental, programou-se resgatar, durante os dois encontros presenciais, as quatro situações propostas durante a OI-2 acrescidas das contribuições feitas pelo grupo ao longo da situação de formação, de maneira que esse conjunto de recursos balizasse o trabalho de elaboração e organização da aplicação da SD por parte dos participantes. 
Para que os participantes experimentassem a situação planejada, foram elaborados uma configuração didática e um modo de execução que formaram a OI-3. O espaço físico planejado para tal foi o mesmo pensando na OI-2 (Figura 5), isto é, os dois encontros deveriam ocorrer em um dos laboratórios de informática da PUC-SP a fim de potencializar o uso de tecnologia digital durante a elaboração da SD.

Programou-se que a performance didática da OI-3 ofereceria subsídios para um balanço das intenções que foram planejadas, comparadas ao que efetivamente foi alcançado com a situação viabilizada pela OI-3 e que permitisse aos participantes a organização de uma SD para introduzir o ensino de função no $1^{\circ}$ ano do EM a partir da FVSM, bem como o arranjo de sua aplicação nas escolas em que seria aplicada.

Esperou-se que o documento SD, construído a partir do conjunto de recursos mobilizados e/ou utilizados pelo grupo, especialmente ao longo das OIs 2 e 3 para a classe de situações planejada, possibilitasse compreender o fenômeno da gênese documental.

A etapa de aplicação, da fase de execução, foi concebida com o intuito de observar os processos de instrumentalização e instrumentação da gênese documental durante a aplicação da SD, pois esperou-se que os participantes continuassem a mobilizar recursos e desenvolver novos esquemas documentais frente a questões levantadas por estudantes, bem como, na troca de experiências proporcionadas pela aplicação com os colegas de formação.

A aplicação da SD foi planejada para ocorrer em três turmas do $1^{\circ}$ ano do ensino médio com alunos de três participantes da formação, em quatro oficinas durante o período compreendido entre 02 a 22 de novembro de 2019, com previsão de dois encontros presenciais com suporte do ambiente Moodle que ocorreram nos dias 09/11 e 16/11/2019.

Esses encontros presenciais foram planejados com o intuito de proporcionar o compartilhamento de experiências vivenciadas pelos participantes durante o período de aplicação da SD, pois esperava-se que a troca de experiências durante essa etapa faria com que os participantes continuassem a desenvolver e/ou mobilizar esquemas documentais.

Para implementar a etapa de crítica da formação continuada foram planejados dois encontros presenciais, com suporte do ambiente Moodle, realizados nos dias $07 / 12$ e 14/12/2019. 
O objetivo dessa etapa foi proporcionar aos participantes a vivência de uma situação de avaliação coletiva sobre a aplicação da SD. Para isso foi disponibilizado ao grupo o acesso prévio ao conteúdo integral do conjunto de vídeos com as oficinas ministradas pelos participantes em um ambiente de dados compartilhado gdrive. Os participantes deveriam indicar detalhes dos trechos que gostariam de debater com o grupo em um fórum de discussão no ambiente Moodle.

Com intuito de dar suporte à situação de avaliação, foi organizada a OI-4 e para que a situação planejada favorecesse a mobilização de recursos e esquemas documentais pelos participantes, foram elaborados uma configuração didática e um modo de execução. A organização do espaço físico para a realização desses dois encontros presenciais foi similar às OIs anteriores (Figura 5).

Planejou-se que a performance didática da OI-4 oferecesse elementos de análise sobre o que foi planejado na configuração didática e modo de execução no sentido de possibilitar construir um balanço acerca da situação de crítica e discussão sobre a aplicação da SD. Esperou-se que a situação viabilizada pela OI-4 permitisse o enriquecimento do documento SD a partir da crítica e reflexão da prática profissional dos participantes, ocasião em que seria possível continuar o acompanhamento da evolução de sua documentação tendo em vista as outas sequências construídas na OI-1 e OI-3. A fase de execução pode ser esquematizada como mostra a Figura 6.

Figura 6 - Estrutura de funcionamento da Fase de Execução

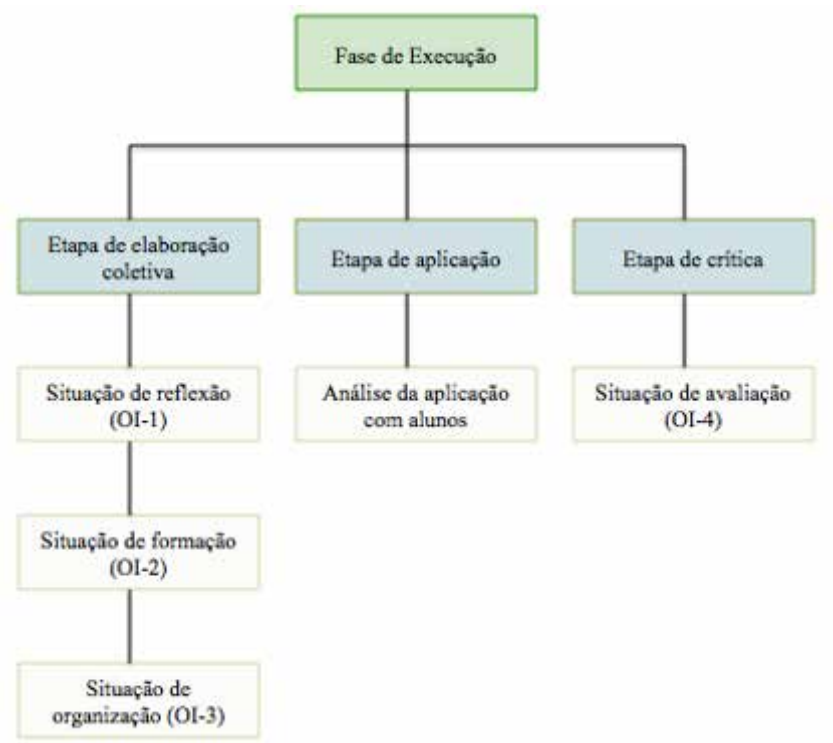

Fonte: Produção dos autores. 


\section{CONSIDERAÇÕES FINAIS}

O acompanhamento do trabalho de documentação dos professores é um processo complexo. Os cinco princípios da metodologia de investigação reflexiva oferecem um leque amplo de opções para o acompanhamento das mais diferentes facetas do trabalho documental dos professores que envolvem o estudo de fenômenos que se desenvolvem em longos períodos, como a gênese documental ou mesmo a evolução de esquemas. Por essa razão, a quantidade de dados obtidos durante os acompanhamentos é considerável e constitui-se em um grande desafio, não apenas organizá-los, bem como dispor de um conjunto de ferramentas metodológicas para auxiliar na sua análise.

Com o intuito de adaptar os princípios propostos pela metodologia de investigação reflexiva à nossa problemática, utilizamos algumas estratégias já experimentadas com sucesso em outros estudos tais como observação fora da sala de aula, entrevista individual ou mesmo a RESR durante a primeira fase da formação continuada que intitulamos preparação e desenvolvemos uma ferramenta de acompanhamento do trabalho documental dos participantes durante a fase de execução.

Esse dispositivo constituiu-se da vivência de um conjunto de situações profissionais articuladas por OIs que nos permitiu identificar esquemas documentais e classes de situações mobilizadas pelos participantes da formação continuada, durante o processo de elaboração, aplicação e crítica de uma SD para introduzir o ensino de função.

Se por outro lado encontramos algumas dificuldades em implementar ferramentas como o diário de bordo ou a visita aos sujeitos de pesquisa, por outro, entendemos que os princípios da metodologia proporcionaram o desenvolvimento de um dispositivo capaz de oferecer respostas à nossa problemática, à luz dos referenciais teóricos da ADD e OI.

\section{REFERÊNCIAS}

ALMOULOUD. S. Modelos de ensino/aprendizagem baseado em situaçõesproblema: aspectos teóricos e metodológicos. REVEMAT. Florianópolis (SC). V. 11. N. 2. P. 109-141. 2016.

ASSIS, C. F.C. Diálogo Didático Matemático na EaD: Uma Perspectiva para o Ensino e Aprendizagem em Fóruns no Moodle. Tese de Doutorado. UFPE. 2010 . 
BRASIL. BNCC. Base Nacional Curricular - Ensino Médio. Ministério da Educação. Brasil. 2018.

BRASIL. PCN+. Orientações educacionais complementares aos Parâmetros Curriculares Nacionais. Ciências da Natureza, Matemática e suas Tecnologias. Ministério da Educação e Cultura. 2000.

BROUSSEAU, G. Fondements et méthodes de la Didactique des Mathématiques. Recherches en Didactique des Mathématiques, Grenoble: La Pensée SauvageÉditions, 1986.

DRIJVERS, P.; DOORMAN, M.; BOON, P.; REED, H.; GRAVMEIJER, K. The Teacher and the Tool: instrumental orchestrations in the technology-rich mathematics classroom. Educational Studies in Mathematics, Berlin Hidelberg, v. 75, n. 2, p. 213-234, Springer Netherlands, 2010.

ELIA, I., PANAOURA, R., ERACLEOUS, A., GAGATSIS, A. Relations between secondary pupils' conceptions about functions and problem solving in different representations. International Journal of Science and Mathematics Education. n. 5(3). p. 533-556. Research Gate. 2006.

EVES, R. Subject matter knowledge for teaching and the case of functions. Educational Studies in Mathematics. n. 21. p. 521-544. Springer Link. 1990.

GUEUDET, G.; TROUCHE, L. Du travail documentaire des enseignants: genèses, collectifs, communautés. Le casdes mathématiques. Education et didactique, Rennes, 2, 3, 7-33. 2008.

GUEUDET, G.; TROUCHE, L. Investigation Réflexive des gêneses documentaires des enseignats. $\mathrm{s} / \mathrm{d}$.

HAMMOUD, R. Le Travail collectif des professeurs en chimie comme levier pour la mise en ceuvre de démarches d'investigation et le développement des connaissances professionnelles. Contribution au développement de l'appoche documentaire du didactique. Tese de doutorado. L'Université Claude Bernard Lyon 1 e L'Université Libanaise. 2012.

HUH, Y. E. Función definida por partes. Un análisis histórico - didáctico referente a su tratamiento escolar. (Tesis de licenciatura). Universidad Autónoma de Yucatán, México. 2009.

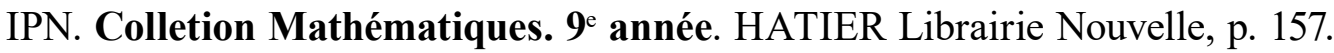
Rep. De Mali. 1991.

LAUDARES, J. B. O Conceito e a Definição em Matemática: Aprendizagem e Compreensão. Encontro Nacional de Educação Matemática. Curitiba. 2013. 
LUCENA, R. Metaorquestração Instrumental: um modelo para repensar a formação de professores de Matemática. Tese de Doutorado. UFPE. 2018.

MESSAOUI, A. Développement de l'expertise documentaire des professeurs dans des situations de mutations de leur enseignement: le cas de professeurs de mathématiques et d'anglais. Tese de Doutorado. L'Ecole Normale Supérieure de Lyon. 2019.

NCH SOFTWARE. Express Scribe. Disponível em: https://www.nch.com.au/ scribe/index.html . Acesso em: 19 Set. 2018. 2020.

OLIVEIRA, N. Conceito de Função: Uma abordagem do processo ensinoaprendizagem. Dissertação de Mestrado. PUC-SP. 1997.

ROCHA, K. D. M. Uses online resources and documentational trajectories: the case of Sésamath. In: Fan L, Trouche L, Rezat S, Qi C, Visnovska J (eds) Research on mathematics textbooks and teachers' resources: advance and issues. Cham, p. 235-258. 2018.

SABRA, H. Contribuition à l'étude du travail documentaire des enseignants de mathématiques: les incidents comme révélateurs des rapports entre documentations individualle et communautaire. Tese de Doutorado. L'Univsersite Claude Bernard Lyon 1. 2011.

TROUCHE, L. Managing the Complexity of Humam/Machine Interactions in Computerized Environments: Guiding Students' Command Process Through Instrumental Orchestrations. International Journal of Computers for Mathematical Education. n. 281. 2004.

TROUCHE, L., GUEUDET, G., PEPIN, B. Documentational Approach to Didatics. In S. Lerman (ed.). Encyclopedia of mathematics education. Cham: Springer. 2018.

VERGNAUD, G. Toward a cognitive theory of practice. In A. Sierpinska, \& J. Kilpatrick (eds.), Mathematics education as a research domain: A search for identity (p. 227-241). Dordrecht: Kluwer. 1998.

WANG, C. An investigation of mathematics teachers' documentation expertise and its development in collectives: two contrasting cases in China and France. Tese de Doutorado. Université de Lyon. 2019.

XAVIER NETO, A. L. Um estudo da Gênese Instrumental para a função de uma variável real com várias sentenças. Dissertação de mestrado. PUC-SP. 2016. 
XAVIER NETO, A. L., SILVA, M. J., TROUCHE, L. A construção de atividades para o ensino de sequências numéricas: Uma análise pela lente da Abordagem Documental do Didático. Educação Matemática e Pesquisa. PUC-SP. 2019. 